\title{
Development of Software for Early Failure Detection and Prevention in Technical Systems Subjected to Normal Distribution until Failure
}

\author{
Branko Savic \\ The Higher Technical \\ Education School of \\ Professional Studies, \\ Novi Sad, Serbia
}

brsavic@yahoo.com

\author{
Nebojsa Nikolic \\ Faculty of Technical Sciences, \\ University of Novi Sad, \\ Novi Sad, Serbia
}

\begin{abstract}
Through the application of the authors' mathematical model developed for early detection and prevention of failures in technical systems a need has arisen to create software that will ease the usage of the model. The development procedure of the mathematical model for early detection and prevention of technical systems failures is not of interest for its application, and the application is, due to its complexity, rather difficult for the final user. Because of this, the aim is to make such software that will take into account all factors of the mathematical model for early detection and prevention of failures in technical systems enabling the user a simple calculation of the optimal moment of diagnostics of the state. Therefore, the starting data herein would be the final formula of the developed mathematical model, and the software user should know only the input data for his system. The output data for the user would be the optimal moment of diagnostics of the state of the technical system. This software would be applicable in most technical systems, but this paper gives an example of its usage in printing presses.
\end{abstract}

Keywords: mathematical models, software, early detection and prevention failure, technical diagnostics.

\section{Introduction}

There are technical systems in which the occurrence of failure must be prevented, such as aviation, military and other industries, where the appearance of failure brings risk to the people lives and goods (Bengtsson, 2002). To prevent a failure, it is necessary to find an alternative solution. In other words, it is needed either to provide the replacement for the defective part that is acti-

Material published as part of this publication, either on-line or in print, is copyrighted by the Informing Science Institute. Permission to make digital or paper copy of part or all of these works for personal or classroom use is granted without fee provided that the copies are not made or distributed for profit or commercial advantage AND that copies 1) bear this notice in full and 2) give the full citation on the first page. It is permissible to abstract these works so long as credit is given. To copy in all other cases or to republish or to post on a server or to redistribute to lists requires specific permission and payment of a fee. Contact 0HPublisher@InformingScience.org to request redistribution permission. vated at the moment of failure of the original one, or to predict the moment of failure and respond to it in order to prevent its appearance. It is not always possible to replace the defective part with another one, so in these cases another solution should be found i.e. the failure occurrence should be predicted and prevented.

The aim of the paper is to determine when is the optimal moment to perform 
the state diagnosis process of the technical system and in this manner to obtain a time picture of possibilities of failure occurrence on a technical system parts. Since the diagnosis requires certain costs, the optimal moment of the diagnosis process regarding the costs decrease is also determined here. In this way it can be detected in which moments during operation of technical systems a failure can occur, and how to react to prevent the failure. All this is done so that the costs will be minimized, too.

The authors developed the model SAV-TT05B, which enables the determination of the optimal moment of state diagnosis of the observed technical system part knowing the distribution law of the part operation until the moment of failure (Powell, 2002). It is also necessary to know the expenses of the state diagnosis process and the expenses of the lost production if the failure is not detected at the right moment. Diagnosis at the right time can predict the possibility of a failure and thus affect its prevention. The final expression for determining the optimal moment of state diagnosis according to the model SAV-TT05B, in case of normal distribution of failure is (Authors, 2005):

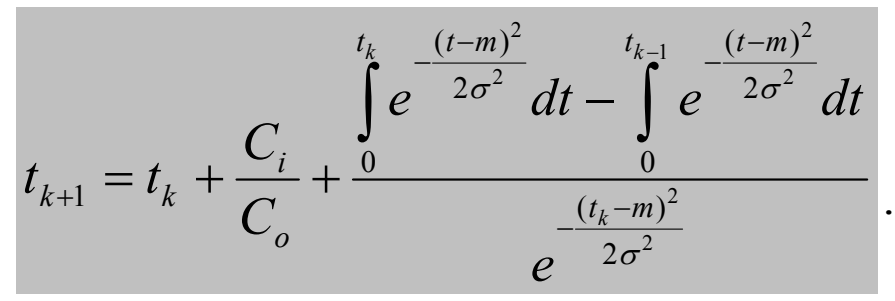

In the previous expression there are the quantities:

$t_{k}$ - k-th optimal moment to perform status diagnosis of a machine part, where $\mathrm{k}=1,2,3, \ldots \mathrm{n}$,

$C_{i}$ - the costs of diagnosis process of the machine part state,

$C_{o}$ - costs of lost production due to the failure of the machine part,

$\sigma$ - standard deviation,

$m$ - mean operation time and

$t$ - moment of failure occurrence.

It is seen from the previous text that the application of the developed model requires knowledge of mathematical functions in a high degree. Hence, the goal of this paper is imposed, i.e. to facilitate the implementation of the model, and that is possible by development of the software package. In this software package the user, i.e. the maintainer who wants to apply the developed model does not need to know the mathematical functions used in the previous expression, but should just enter the required information in certain fields and then by pressing the appropriate button he obtains the optimal moments when to perform diagnosis process for the given part or the system.

\section{Development of Software for the Model Application}

The software has been developed using Macromedia Flash Professional 8. After setting up a graphical environment, the program has been written based on the model. Thereafter object linking and the program activation have been performed what is shown in the Figure 1.

Finally, after performing all the activities and tests, the executable program that is shown in Figure 2 has been obtained. 


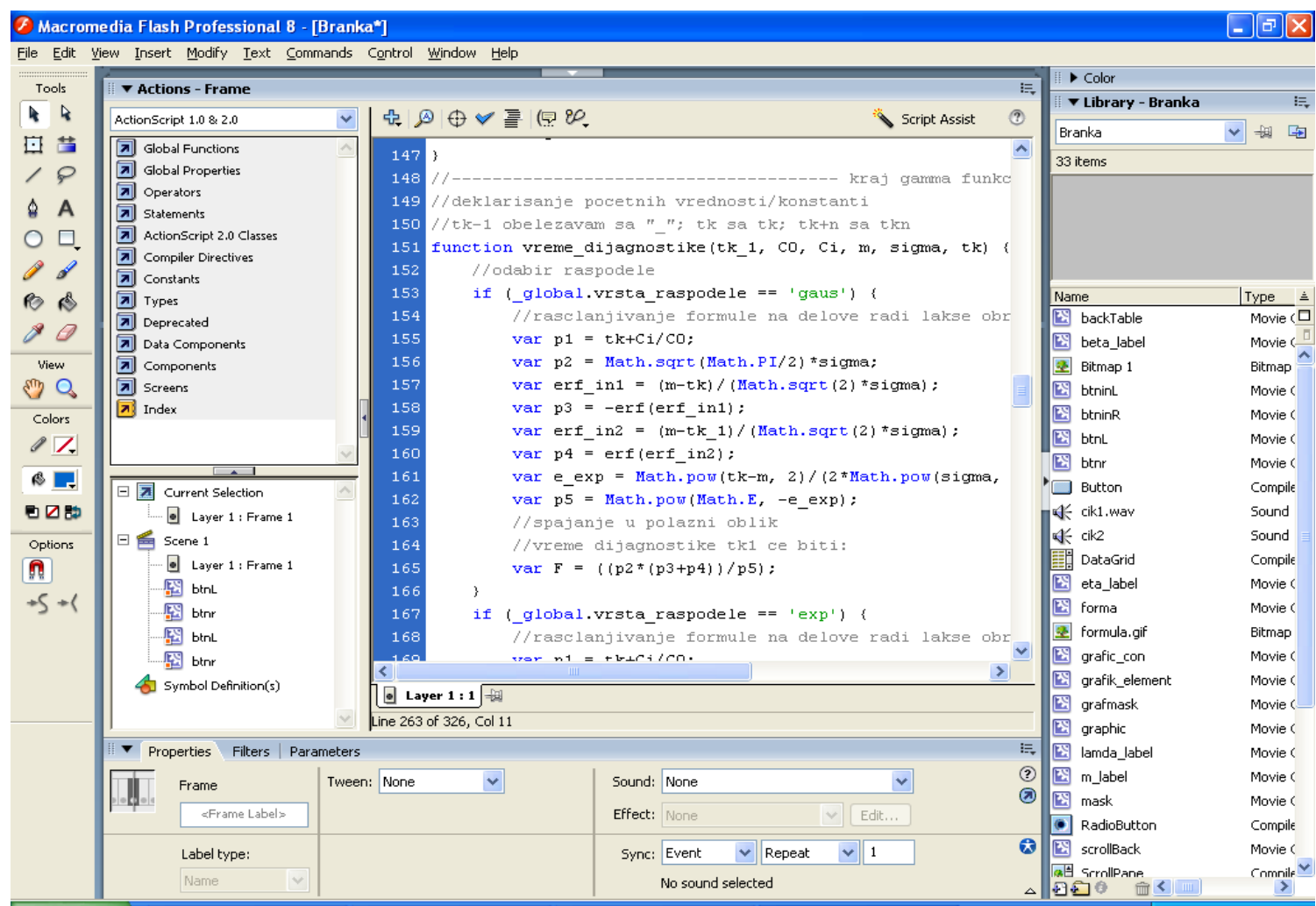

Figure 1. A program page and objects linking in the software package

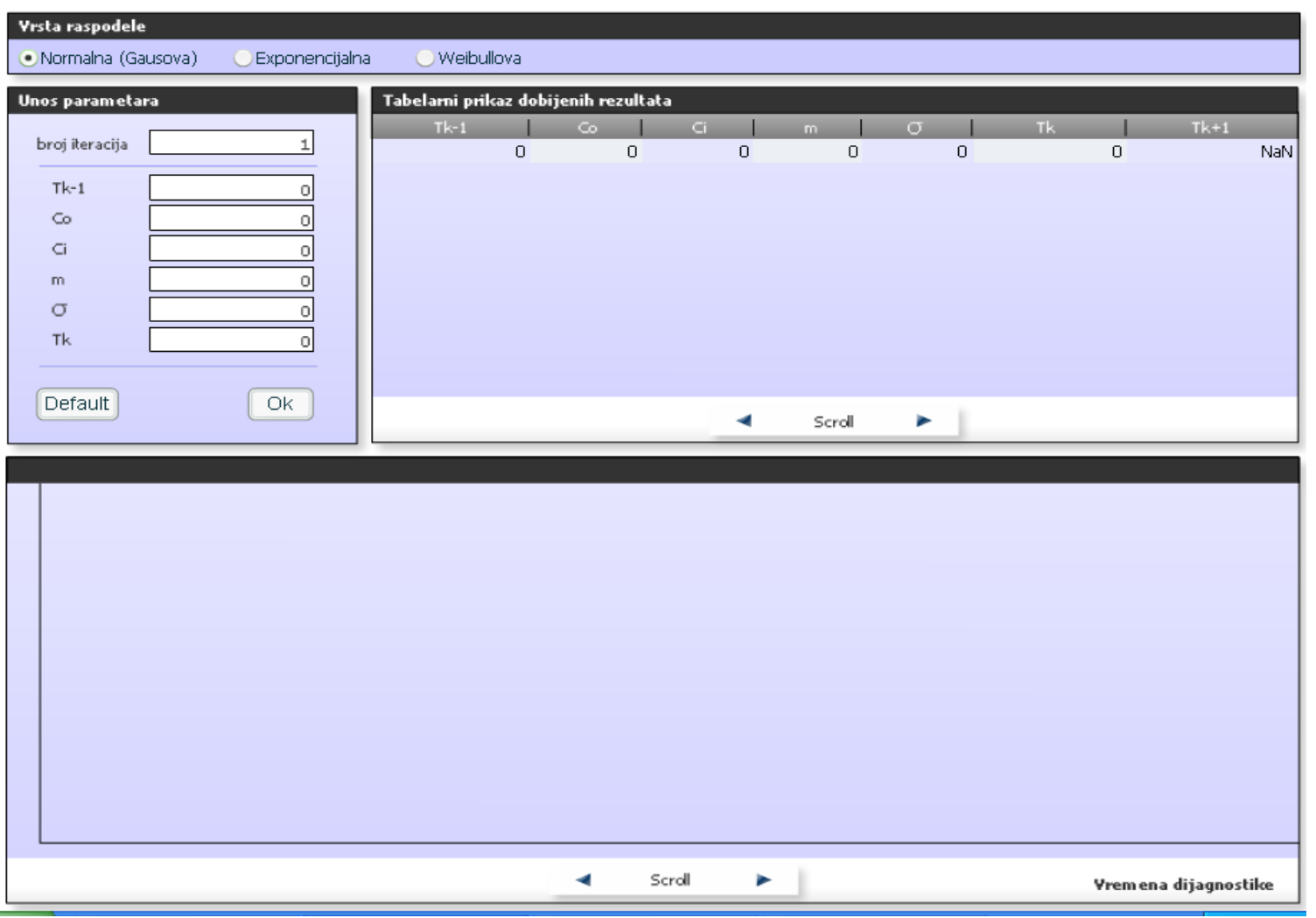

Figure 2. User interface look of the developed software package for determination of the optimal moment of system part state diagnosis 
Figure 2 shows that there are four windows in the developed software package, such as: the distribution type, the data entry, the table review of the obtained results and the graphical representation of the results.

Observing the first window one can see that the goal is to develop software for three most common types of distribution: normal, exponential and Weibull distribution. Depending on the established distribution of the observed element the distribution type is selected in the field "type of distribution". When the software is developed for normal distribution, the environment shown in Figure 2 is obtained.

The second window is used for data entry. In the field "number of iterations" an approximate number of state diagnoses is entered, usually higher than necessary. If such a number of diagnoses is not needed, then the software will remove the excessive ones, what will be seen from interpretation of the results obtained.

In the program it is necessary to determine the unknown $t_{k+1}$, and it is in fact the next moment of diagnosis, or rather the optimal moment of state diagnosis which is calculated. The moment $t_{k-1}$ is taken to be equal to 0 , when the first moment of state diagnosis is determined because no state diagnosis is performed until that moment. Furthermore, to determine the first moment of state diagnosis, the $t_{k}$ is taken to be equal to the moment when a failure occurred for the first time on the observed part.

\section{Application of the Software for Optimal Moment of State Diagnostics Determination}

To test the model gear failures on the package printing machine (flexographic printing machine) were observed (Bjelica, 2005; Jardine, 1999), as shown in Table 1.

\begin{tabular}{|c|c|c|c|c|c|c|c|}
\hline \multicolumn{7}{|c|}{ Table 1: Moments of gear failure occurrences } \\
[hour] \\
\hline 4530 & 12555 & 19956 & 24960 & 28541 & 33584 & 42154 & 54991 \\
\hline 6570 & 13456 & 20521 & 25047 & 29021 & 34564 & 44589 & 58574 \\
\hline 7250 & 15011 & 22035 & 25684 & 29874 & 35541 & 45025 & \\
\hline 9211 & 15298 & 23545 & 26581 & 31254 & 36732 & 46058 & \\
\hline 10521 & 16521 & 24547 & 26965 & 31599 & 37852 & 47052 & \\
\hline 11259 & 19021 & 24958 & 27548 & 32588 & 39584 & 50147 & \\
\hline
\end{tabular}

By processing the data and testing the hypothesis of normal distribution (Dovich, 1990), the input data for the program have been obtained: $t_{k-1}=0, t_{k}=4.500$ hours, $m=27.792 \mathrm{i} \sigma=13.428$ hours and costs $C_{i}=100$ m.u, $C_{o}=50$ m.u (m.u. - money unit).

By entering these values into the program and assuming the number of iterations 30 , and then activating the program, the values of optimal moments for diagnosis of the state appear in the window ,table review of the results obtained“ in the column $t_{k+1}$, as shown in figure 3 . Also, in the field ,graphical review of the results obtained" in the same figure optimal moments of diagnostics of the state of the flexographic machine gears have been shown in the form of time axis. 


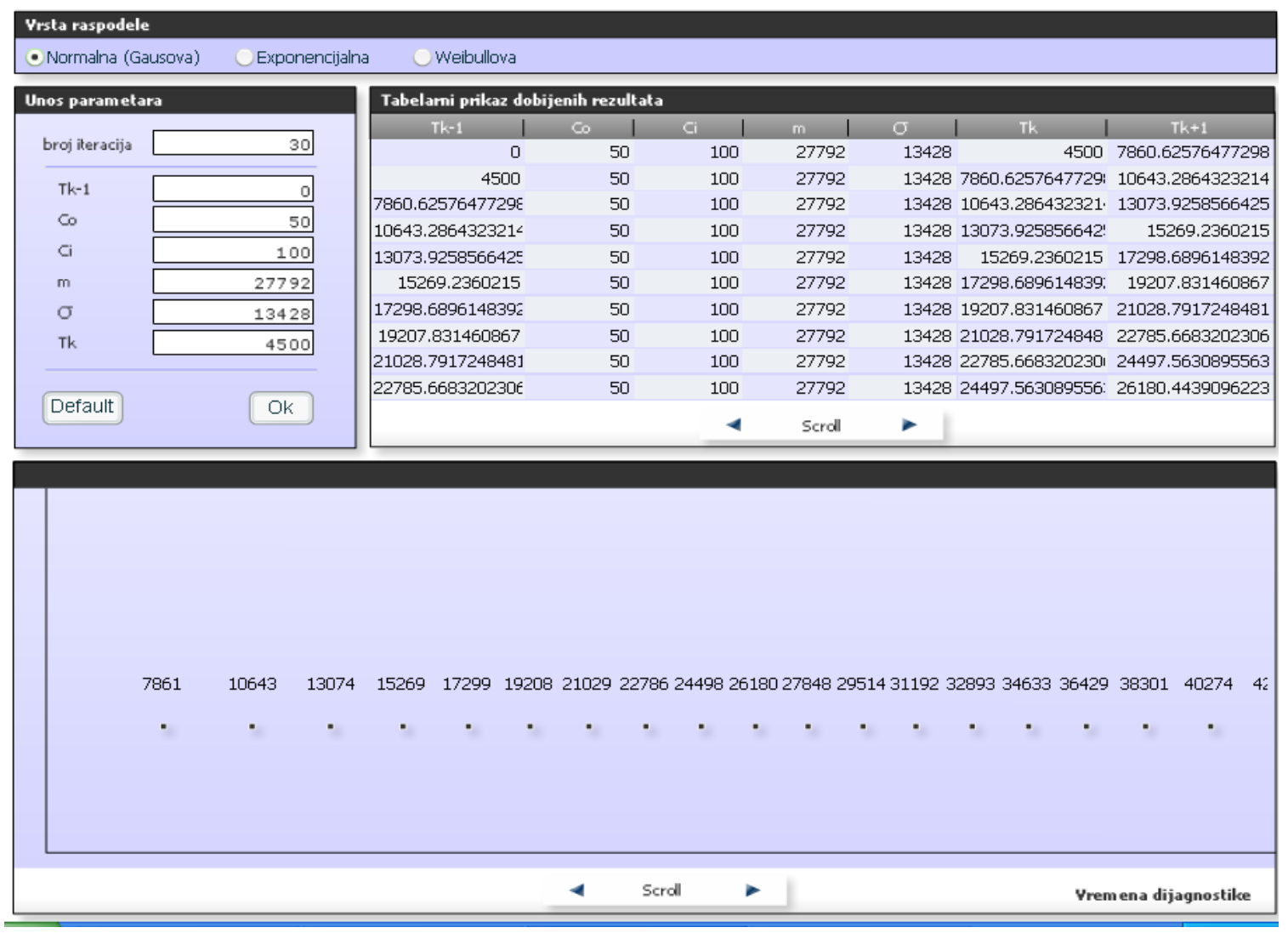

Figure 3: The program overview and its application for optimal moment of diagnostics

Thorough state diagnosis moments calculated according to the model developed SAV-TT05B, after application of the program have been given in Figure 4.

The table also shows the parameters used to calculate the optimal moment of state diagnosis $t_{k+1}$.

Figure 4 shows that the last two moments of diagnosis are outside the time range. The last four moments of state diagnosis do not have practical application, because the last gear failed after 58,574 hours of work. Hence, it is necessary to reduce the assumed number of the iterations required by six. One can see that 24 state diagnostics of the gears observed are needed in the intervals obtained (column $\mathrm{t}_{\mathrm{k}+1}$ ).

What is important to verify the correctness of the software developed is the result match for the optimal moments of diagnostics in Figure 4 with the of the failure occurrence layout for the gears of the given machine. So calculation of the optimal moments of state diagnostics of this element shows that state diagnoses are most frequent around the mean operation time until failure occurrence, while before and after that time the number of diagnoses decreases (Figure 5). 


\begin{tabular}{|c|c|c|c|c|c|c|}
\hline Tk-1 & $\omega$ & $\mathrm{Ci} \quad \mathrm{I}$ & $\mathrm{m} \quad \mathrm{I}$ & $\sigma$ & Tk & I Tk+1 \\
\hline 0 & 50 & 100 & 27792 & 13428 & 4500 & 7860.62576477298 \\
\hline 4500 & 50 & 100 & 27792 & 13428 & 7860.6257647729 & 10643.2864323214 \\
\hline $7860.6257647729 \varepsilon$ & 50 & 100 & 27792 & 13428 & 10643.286432321 & 13073.9258566425 \\
\hline $10643.286432321^{<}$ & 50 & 100 & 27792 & 13428 & $13073.925856642 !$ & 15269.2360215 \\
\hline 13073.9258566425 & 50 & 100 & 27792 & 13428 & 15269.2360215 & 17298.6896148392 \\
\hline 15269.2360215 & 50 & 100 & 27792 & 13428 & 17298.689614839: & 19207.831460867 \\
\hline $17298.689614839_{c}^{-}$ & 50 & 100 & 27792 & 13428 & 19207.831460867 & 21028.7917248481 \\
\hline 19207.831460867 & 50 & 100 & 27792 & 13428 & 21028.791724848 & 22785.6683202306 \\
\hline 21028.7917248481 & 50 & 100 & 27792 & 13428 & 22785.668320230 & 24497.5630895563 \\
\hline 22785.6683202306 & 50 & 100 & 27792 & 13428 & $24497.563089556:$ & 26180.4439096223 \\
\hline $24497.563089556:$ & 50 & 100 & 27792 & 13428 & 26180.443909622 & 27848.3860778787 \\
\hline $26180.443909622 \approx$ & 50 & 100 & 27792 & 13428 & 27848.386077878 & 29514.4824196633 \\
\hline 27848.386077878 & 50 & 100 & 27792 & 13428 & 29514.482419663: & 31191.5918522043 \\
\hline 29514.482419663: & 50 & 100 & 27792 & 13428 & 31191.591852204: & 32893.0437978325 \\
\hline $31191.591852204 \vdots$ & 50 & 100 & 27792 & 13428 & $32893.043797832 !$ & 34633.4009352883 \\
\hline 32893.043797832ᄃ & 50 & 100 & 27792 & 13428 & $34633.400935288:$ & 36429.3972117498 \\
\hline $34633.400935288:$ & 50 & 100 & 27792 & 13428 & 36429.397211749: & 38301.2180494055 \\
\hline $36429.397211749 \varepsilon$ & 50 & 100 & 27792 & 13428 & $38301.218049405 !$ & 40274.3992869785 \\
\hline 38301.2180494055 & 50 & 100 & 27792 & 13428 & $40274.399286978 !$ & 42382.8535201528 \\
\hline 40274.3992869785 & 50 & 100 & 27792 & 13428 & 42382.853520152 & 44674.0428253257 \\
\hline $42382.853520152 \varepsilon$ & 50 & 100 & 27792 & 13428 & 44674.042825325 & 47218.5280875683 \\
\hline 44674.042825325; & 50 & 100 & 27792 & 13428 & 47218.528087568 & : 50129.3398885309 \\
\hline 47218.528087568: & 50 & 100 & 27792 & 13428 & 50129.3398888530 & 53606.4413466582 \\
\hline $50129.339888530 \subseteq$ & 50 & 100 & 27792 & 13428 & 53606.441346658 & 58058.3077095646 \\
\hline $53606.441346658 c^{-}$ & 50 & 100 & 27792 & 13428 & 58058.3077095641 & | 64538.669888719 \\
\hline $58058.307709564 \epsilon$ & 50 & 100 & 27792 & 13428 & 64538.669888719 & 77342.5065499108 \\
\hline 64538.669888719 & 50 & 100 & 27792 & 13428 & 77342.506549910 & 168527.524762024 \\
\hline $77342.506549910 \varepsilon$ & 50 & 100 & 27792 & 13428 & 168527.52476202 & $\cdot 2.68811213752293 \mathrm{e}$ \\
\hline $168527.52476202^{2}$ & 50 & 100 & 27792 & 13428 & 2.6881121375229 & $\mathrm{NaN}$ \\
\hline $2.6881121375229:$ & 50 & 100 & 27792 & 13428 & $\mathrm{NaN}$ & $\mathrm{NaN}$ \\
\hline
\end{tabular}

Figure 4: Optimal moments of performing diagnostic tests of state of flexographic printing machine gears obtained with the help of the software package and based on the developed model SAV-TTO5B

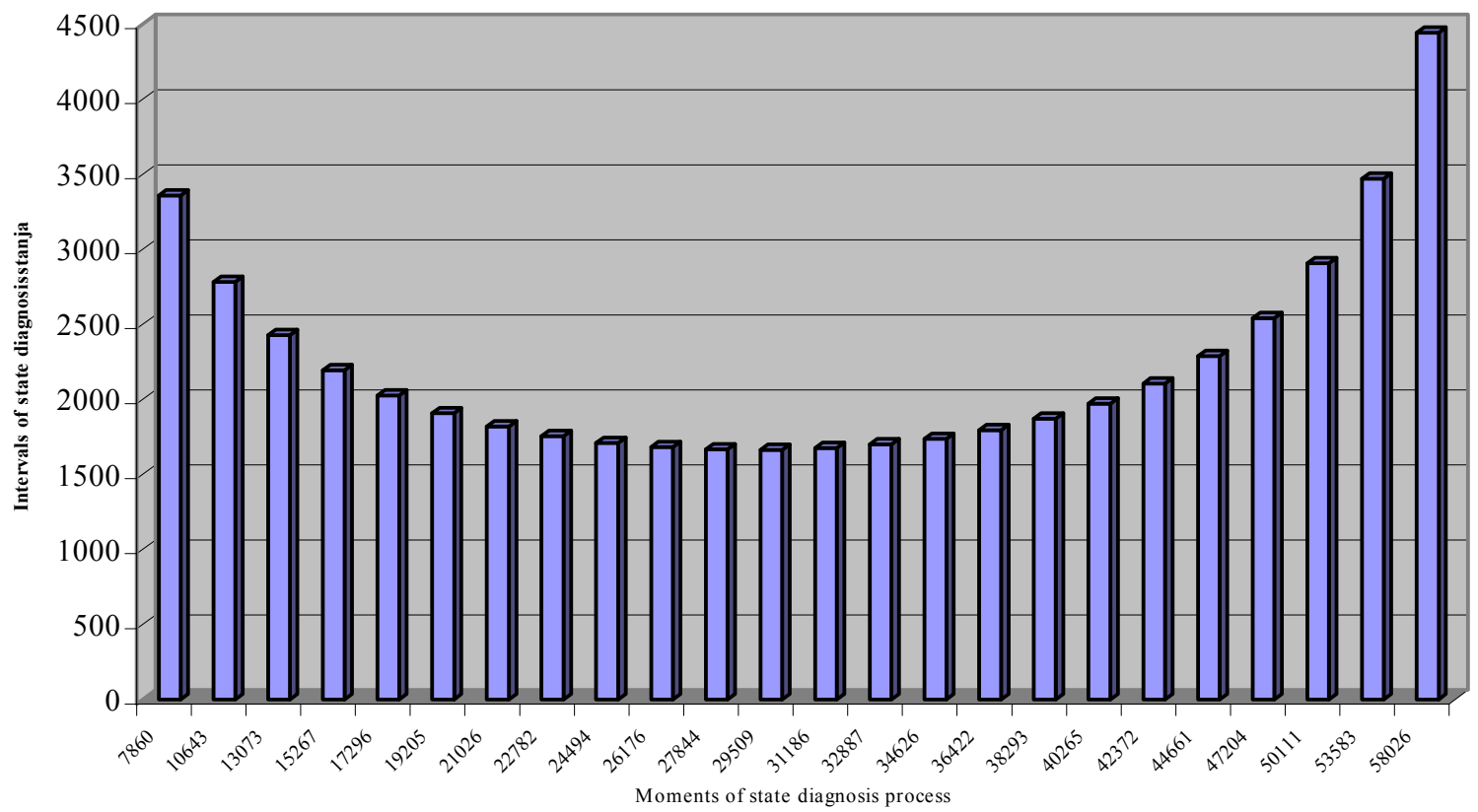

Figure 5: Graphical overview of moments of state diagnostics of the flexographic printing machine gears calculated according to the model developed 
Here is also obvious that the optimal moments of state diagnostics obtained with the help of this software package behave in accordance with expectations for normal distribution. So it can be seen that the state diagnoses are more frequent around the mean operation time, while the number of diagnoses decreases as it moves away from that time. Therefore it can be concluded that the developed software package is suitable for determining optimal moment of state diagnosis for those parts that have normal failure distribution law provided that the model SAV-TT05B is used to determine the optimal moment. Application of the developed software on other machines subjected to normal failure distribution confirms correctness of the software in similar way.

\section{Conclusion}

Based on the above, it is seen that it is possible to develop software that implements the model SAV-TT05B to determine optimal moment of state diagnosis by minimizing total costs depending on time. The developed software package gives optimal moments of state diagnosis of the elements observed. Thus a failure can be predicted and prevented before it is too late. Application of the model is quite simplified with a help of the software, because a user does not have to deal with complex mathematical operations for determination of optimal moment of state diagnosis but only to enter certain input data into the program. Thereafter by pressing a single button optimal moments of state diagnosis of the elements observed are obtained without getting involved into the model structure and the program functioning. By application of the software and the model developed, number of failures and maintenance costs would be reduced to a great extent, that would contribute to production improvement.

\section{Reference}

Bengtsson, M. (2002) Condition based maintenance in technical systems. Department of Innovation. Design and Product Development Eskilstuna. Sweden.

Bjelica, M., Adamovic, Z., \& Savic, B. (2005). Dijagnostika stanja grafičkih mašina u D.O.O. MULTITEC i primena modela održavanja u cilju poboljšanja stanja. Projekat. Zrenjanin. Serbia

Dovich, R.A. (1990). Reliability statistics. ASQ Quality Press. Milwaukee. USA

Gonzalez, J, (2006). Macromedia Flash Professional 8 hands-on training. Peachpit Press

Jardine, A.K.S., Joseph, T., \& Banjevic, D. (1999). Optimizing condition-based maintenance decisions for equipment subject to vibration monitoring. Journal of Quality in Maintenance Engineering, 5(3), 192202.

Powell, J. (2002). An introduction to integro-difference equations. Department of Mathematics and Statistics Utah State University. USA

Savić, B. (2005): Unifikacija i sistematizacija modela za utvrđivanje optimalnog perioda tehničke dijagnostike i njihova primena na grafičkim mašinama; doktorska disertacija Zrenjanin. god. Serbia. 


\section{Biographies}

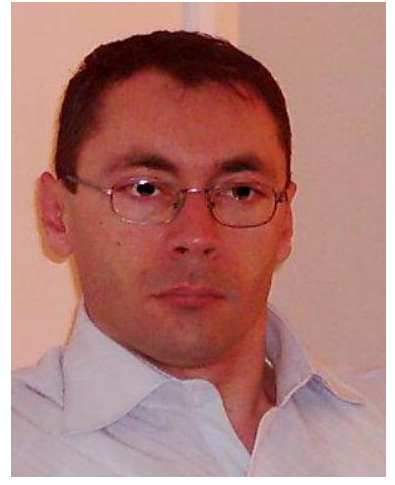

Dr. Branko Savic was born on 03 March 1969th in Loznica, Serbia. He graduated in 1994. at the University of Novi Sad, Faculty of Technical Sciences, Department of Mechanical Engineering Department of manufacturing systems, robotics and automation. At the University he defended his magister thesis in the field of machine maintenance. He is employed at the School of Professional Higher Education Novi Sad, Serbia, as a teaching and research professor. His scientific areas of interest are graphics machines, reliability, from which he published, as an author or a coauthor, more than 55 scientific and professional papers at national and international conferences or in local journals. He participated in realization of several scientific research projects. He is also interested in software development and has taken part in several software development projects with commercial application.

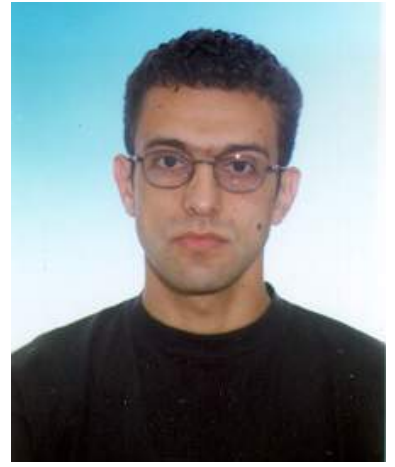

Mr. Nebojsa Nikolic was born on 27 January 1969th in Loznica, Serbia. He graduated in 1994. at the University of Novi Sad, Faculty of Technical Sciences, Department of Mechanical Engineering Department of manufacturing systems, robotics and automation. At the University he defended his master thesis in the field of internal combustion engines. He is currently employed at the Faculty of Technical Sciences as a teaching and research assistant. His scientific areas of interest are dynamics of internal combustion engines and internal combustion engines equipment, from which he published, as an author or a coauthor, more than 35 scientific and professional papers at national and international conferences or in local journals. He participated in realization of several scientific research projects. He is also interested in software development and has taken part in several software development projects with commercial application. 